\title{
ANTIGUIDADES ROMÂNTICAS: ONDE SE ENCONTRAM OS GUERREIROS ANTIGOS E SELVAGENS
}

\author{
Maria Edith Maroca de Avelar Rivelli de Oliveira* \\ Pedro Ipiranga Júnior**
}

Recebido em: 09/03/2020 Aprovado em: 31/03/2020

RESUMO: As mudanças mentais ocorridas no século XVII e a resultante separação entre os antigos e os modernos, nos séculos seguintes (XVIII e XIX) acarretaram transformações semânticas substanciais na relação com a herança clássica. Entre essas mudanças (bem demonstradas pelo culto romântico da originalidade), destacam-se as novas categorias e formas em que a experiência humana foi modelada, cujos modelos teóricos e narrativos propunham um novo gênero: a história nacional. A certeza de superação dos antigos foi também responsável pelo plural de antiguidades nacionais. Surpreendentemente, porém, essas novas narrativas revelar-se-iam em grande dívida para com a tradição clássica: principalmente, na formulação heroica dessas novas antiguidades.

PALAVRAS-CHAVE: Ferdinand Denis; historiografia francesa; história do Brasil; Romantismo; Antiguidade Clássica.

\section{ROMANTIC ANTIQUITIES: WHERE ANCIENT AND SAVAGE WARRIORS MEET AMONG THEMSELVES}

* Doutoranda do Programa de Pósgraduação em História, Instituto de Ciências Humanas e Sociais, Universidade Federal de Ouro Preto.

mariaepiaf@gmail.com

(iD)

** Professor

Associado, Departamento de Polonês, Alemão e Letras Clássicas, Universidade Federal do Paraná.

junioripiranga7@hotmail.com

\footnotetext{
ABSTRACT: The mental changes that took place in the 17th century, and the resulting separation between the Ancients and the Moderns, in following centuries (18th and 19th centuries) have suffered substantial semantic transformations in the relation with the Classical Heritage. Among these changes (well showed by the romantic cult of originality) the new categories and forms in which the human experience was modelled stand out, whose theoretical and narrative models were shaped in a new genre: national history. The certainty of overcoming the Ancients would also engender a plurality of National Antiques. Surprisingly, these
} 
narratives would carry on the classical tradition as a model; mainly, in the heroic formulation of these New Antiques.

KEYWORDS: Ferdinand Denis; French historiography; history of Brazil; Romanticism; Classical antiquity.

\section{DE RUPTURAS E PERMANÊNCIAS}

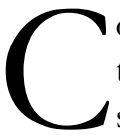

om a emergência do historicismo e a percepção centro-europeia de uma nova temporalidade: linear e progressivamente infinita ${ }^{1}$ no século XVIII, a Antiguidade sofreu um deslocamento semântico e ideológico concretizado graças a novas disciplinas como a arqueologia, etnologia e filologia. A partir da reconsideração visual, táctil e neolinguística do passado, e decorrente rearranjo dos modelos arqueográficos, a antiguidade torna-se plural, segundo a metodologia científica da época. A antiguidade greco-romana se torna clássica, e concorre, a partir de então como memória, com as diversas antiguidades nacionais, para as quais serve de modelo compreensivo e formal. Os estudos contemporâneos vêm redescobrindo esse fenômeno em sua riqueza interpretativa e poder de atualização da Antiguidade através das reelaborações daquele momento. Não apenas as antiguidades românticas assim elaboradas derivavam de construções clássicas - que de certa forma reafirmavam -, como a própria noção de Antiguidade Clássica se consolida nesse momento, em formato próximo ao que conhecemos hoje. ${ }^{2}$

Este trabalho propõe-se a contribuir com o processo de retomada das antiguidades românticas ao abordar um autor francês em sua original contribuição para a elaboração da antiguidade nacional brasileira. Inspirado pelos padrões liberais franceses, Ferdinand Denis (1798-1890) apresenta, na década de 1820, um primeiro projeto em que a antiguidade nacional, representada pelos índios, é equiparada aos antigos. ${ }^{3}$ Nesse mesmo projeto e nas obras

\footnotetext{
${ }^{1}$ Quanto à mudança na percepção do tempo nesse período e toda a consequente reelaboração da experiência humana e da história, inspiramo-nos em vários autores contemporâneos, cujos conceitos de aceleração do tempo (Koselleck, 2006), mudança no regime de temporalidade (Hartog, 2013), ou cronótopo tempo histórico (Gumbrecht, 1998), nos parecem complementares ou equivalentes, ao tratar, a partir de abordagens diferenciadas, de um mesmo fenômeno: a conscientização tanto massiva quanto erudita dos centro-europeus, a partir da Revolução Francesa, de que a história sofrera um câmbio inestimável, e a experiência do tempo e da história distanciavam-se inexoravelmente do passado. A sensação de alteridade em relação ao vivido, a cisão entre passado, presente e futuro torna-se a partir de então um elemento diretor, e seu estudo se daria a partir de uma nova História. ${ }^{2}$ Algumas leituras estão no cerne dessa interpretação, instruindo-nos sobre a transformação da antiguidade greco-romana em clássica: $A$ invenção da mitologia (Detienne, 1992); From Paris to Pompeii (Blix, 2009); e ajudando a desvendar a passagem da antiguidade universal para as novas antiguidades nacionais: Les lieux de mémoire (Nora, 1986); As raízes clássicas da historiografia moderna (Momigliano, 2004). ${ }^{3}$ Sobre a aproximação entre antigos e selvagens entre os franceses, cf. Temistocles Cezar (2010) e François Hartog (2013); quanto ao Brasil indicam-se, entre outros, Rodrigo Turin (2011) e Maria
} 
que escreve no período, o autor expande essa proximidade (e expõe involuntariamente as idiossincrasias) em diários, cartas e obras de ficção histórica, em que também a aproximação entre os heróis clássicos e os novos personagens por ele erigidos como (modernos) clássicos nacionais brasileiros revela as continuidades no processo de ruptura.

Tendo isso em vista, este trabalho propõe de início uma apreciação do projeto elaborado pelo erudito francês Ferdinand Denis. Após uma breve descrição da teoria liberal da história e da forma como deve ser executada na narrativa nacional, consideramse algumas de suas obras relacionadas ao Brasil, tanto historiográficas quanto ficcionais e autobiográficas, para a exemplificação das polaridades diversas, entre a originalidade romântica e as continuidades em relação à herança clássica. Sublinha-se a forma de retomada da Antiguidade Clássica, de deuses, heróis e autores clássicos, em sua comparação com índios, negros e outros povos situados pelo autor como na infância da história, assim como é posto em primeiro plano o fundamento adotado da historiografia liberal, o princípio de liberdade incondicional, especificamente, na tessitura do discurso (auto)biográfico e romanesco em alguns de seus textos.

$\mathrm{O}$ artigo divide-se em duas partes, sendo a primeira voltada à teoria da história e à maneira como sua concepção historiográfica revalida os modelos clássicos ao mesmo tempo em que os desloca de seu sentido único; na segunda parte verificam-se as narrativas autobiográficas e de viajantes, assim como textos de caráter literário do mesmo período (décadas de 1810-1820), em que se observa, repetidamente, o aguçado sentido etnográfico e erudito do autor, confirmando-se uma formação mais voltada à erudição e à historiografia - mesmo quando literária. ${ }^{4}$

\section{A perda do halo}

Como artefatos atemporais se tornaram vestígios históricos, carregados de informações culturais vitais? (BLIX, Göran. From Paris to Pompeii)

Com essa pergunta, formulada pelo crítico literário Göran Blix (2009), somos inseridos em uma questão essencial para este artigo: a historicização da Antiguidade Clássica ocorrida a partir do século XVII. Blix aponta para o distanciamento entre o passado Clássico e os Modernos, momento em que os modelos antigos, anteriormente atemporais, tornaramse a partir de então datados e de eficácia comprometida. Se até pouco antes a civilização

Edith Maroca de Avelar Rivelli de Oliveira (2011).

${ }^{4}$ É importante ressaltar que a maior parte da obra denisiana publicada em vida são estudos de erudição. Quanto às suas incursões no terreno da ficção, elas se remetem, frequentemente, a períodos e fatos históricos, o que reafirma seu interesse em uma narrativa com algum enquadramento histórico ou biográfico, dentro de uma perspectiva romântica (Thierry, 1827) de ficção histórica como narrativa legitimadora do passado (Reizov, 1962; Lukács, 1966; Gossman, 1978). 
ocidental considerava-se naturalmente descendente dos Antigos, tecendo míticas genealogias entre estes e as Nações Modernas, os séculos XVIII e XIX testemunhariam uma realocação temporal e semântica destes antigos, que passam a dividir espaço com as recém-propostas antiguidades nacionais.

Para isso contribuiria a emergência do historicismo, no início do século XIX, inspirado em muito pelos avanços arqueológicos do século anterior e, em paralelo, pelo desenvolvimento da voga arqueográfica das identidades nacionais no mesmo período tarefa doravante obrigatória de eruditos e letrados. Arvorados em "mestres da verdade nacional”, estes eruditos moviam-se pela crença numa essência identitária recuperável através da "escavação" do passado através de artefatos produzidos pelos novos saberes, a arqueologia, a filologia e a etnologia. ${ }^{5}$ Também contribuía, segundo Reinhardt Koselleck (2006), a percepção centro-europeia de uma nova temporalidade, linear e progressivamente infinita, exigindo a forja de novas artes narrativas e heurísticas do passado: ${ }^{6}$ as ciências do homem e sua trajetória no tempo-espaço, cuja elaboração, em formato científico, previa que representassem fórmulas de análise com validade universal, ao mesmo tempo em que pudessem ser aplicadas na apreensão particular das várias nacionalidades, possibilitando a consolidação de sua individualidade pela narrativa histórica. ${ }^{7}$

Nesse sentido esse trabalho propõe, num escopo restrito ao contexto erudito francês do século XIX, uma reflexão inicial sobre aquele momento em que as histórias - locais e universal - se rearranjaram. Para tanto, realiza-se aqui, de início, uma breve apreciação do projeto elaborado pelo erudito francês Ferdinand Denis, "Considerações gerais sobre o caráter que a poesia deve ter no Novo Mundo" (1826), como o primeiro esboço e projeto para as letras e identidade brasileiras em 1826, destacando aí o fenômeno da aproximação entre antigos e selvagens no texto denisiano, como parte do processo amplo de realocação semântica dos antigos, pelo Romantismo francês.

De imediato, assumimos uma avaliação diferenciada sobre Ferdinand Denis - bastante conhecido na historiografia literária brasileira, como iniciador de nossa historiografia literária e grande incentivador de nosso Romantismo, ${ }^{8}$ que neste trabalho será retomado de forma um pouco mais autônoma em relação à tradição literária brasileira, para ressituá-lo ao seu lugar

\footnotetext{
${ }^{5}$ Blix chama a atenção para o uso das metáforas arqueológicas no momento. Não há que penalizar esses autores pela sua inconsciência acerca do caráter mediato do passado que apresentavam.

${ }^{6}$ Cf. Blix, 2009; Momigliano, 2004.

${ }^{7} \mathrm{O}$ caráter eurocêntrico dessa ciência do passado é demasiado importante para não merecer destaque; porém, extremamente amplo para ser tratado aqui.

${ }^{8}$ As referências a Denis na história da historiografia literária brasileira são inúmeras. São referências importantes: Eternamente em berço esplendido - a fundação de uma literatura nacional, de Maria Helena Rouanet (1991); Um romantismo a oeste: modelo francês, identidade nacional, de Ana Beatriz Demarchi Barel (2002), e vários trabalhos de Regina Zilberman sobre o autor, entre os quais destacarei "Ferdinand Denis e os paradigmas da história da literatura" (2006), "O Resumo de História Literária, de Ferdinand Denis: história da literatura enquanto campo de investigação" (2013), "Ferdinand Denis e o Resumo de História Literária" (2018).
} 
de pertença, ${ }^{9}$ entre os historiadores liberais e românticos franceses da primeira metade do século XIX. Para tanto inspira-se essa leitura nas abordagens de cunho linguístico como a Escola de Cambridge (Skinner; Pocock) e a História dos conceitos (Koselleck), a partir das quais se depreenderá seu projeto para o Brasil como parte de uma nova elaboração - francesa e liberal - de história. É como um membro do grupo erudito liberal em verdadeira ebulição litero-política nas décadas de 1810 a 1820 (Mellon, 1958; Gauchet, 2002) que o tradutor e bibliotecário conceberá a forma a ser dada à experiência do tempo brasileira.

\section{UM ERUDITO FRANCÊS}

Ferdinand Denis tornou-se próximo a nós graças a uma permanência de quase quatro anos no Brasil (1816-1819) como membro do consulado francês na Bahia e pela posterior produção de uma vasta bibliografia acerca da história, literatura e etnografia brasileiras em sua longa carreira nas letras francesas. Nas décadas seguintes reforça seus laços com nossos letrados como membro do Instituto Histórico e Geográfico Brasileiro, correspondente de Dom Pedro II, Gonçalves Dias e Francisco Adolfo de Varnhagen, consultor e amigo dos nacionais sobre assuntos de história e erudição e portador das mais altas distinções nacionais, como as grã-cruzes da Ordem da Rosa e do Cruzeiro do Sul.

Consagrou-se (e merece destaque, ainda hoje) por nos proporcionar duas obras pioneiras e de grande repercussão no pensamento nacional: o Résumé de l'histoire du Brésil de 1825, primeira narrativa da Nação independente (e imediatamente traduzido e adotado nas escolas públicas nacionais) e o Résumé de l'histoire littéraire du Brésil (1826), nosso "grito do Ipiranga" na literatura (Zilberman, 2006). Graças a eles Denis sagrou-se um dos pioneiros especialistas em temas brasileiros e importante interlocutor de nossos letrados, cuja sobrevida na memória intelectual brasileira avançou pelo século XX graças ao lugar castiço de fundador da nossa historiografia literária, com o volume de 1826.

Dessa suposta intimidade unilateral, ${ }^{10}$ derivou-se uma percepção "brasiliocêntrica" do autor e suas ideias, cuja forma bem acabada se percebe em Eternamente em berço esplêndido - a fundação de uma literatura nacional, de Maria Helena Rouanet. Resultante de uma tese de doutoramento orientada por Luiz Costa Lima, e publicado em 1991, clássica pela perenidade da tese aí defendida. De forma sumária podemos apresentar a hipótese de Rouanet da seguinte maneira: considerado pela pesquisadora um autor de pequena expressão em seu país, e interessado em aproveitar-se do interesse brasileiro em suas obras sobre o Brasil,

\footnotetext{
${ }^{9}$ Esta perspectiva é abordada mais amplamente no trabalho da tese de doutorado de Maria Edith Maroca de Avelar Rivelli de Oliveira, em andamento.

${ }^{10}$ Em diversos textos do século XIX e XX, Denis é referido como "amigo do Brasil” (Dória, 1912), "francês de alma brasileira" (Souza e Silva, 1890), e epítetos afins, que identificam no autor uma relação afetiva com o país que dificilmente se confirma. A exemplo, cito o fato de que, após a partida em 1819, o erudito jamais tivesse retornado ao Brasil, no que seria muito bem vindo.
} 
Denis teria assumido, desde 1825, uma espécie de compromisso de produzir uma narrativa nacional a partir das expectativas de nossas elites letradas. ${ }^{11}$

O fato de que essa percepção "brasiliocêntrica" sobre Denis só fosse possível ao desvencilhar o autor de seu real contexto foi recentemente destacado pelo historiador literário francês Jean Claude Laborie, em artigo de 2013 intitulado "Estudo de mediações: o caso Ferdinand Denis". Nesse momento o pesquisador da Sorbonne afirma a necessidade de que se reinsira Denis em uma tradição de autores franceses que vai desde o monge Andrés Thevet (século XVI) até o antropólogo Claude Lévi-Strauss (século XX) como parte de uma tradição de personagens franceses cuja passagem pelo Brasil teria transformado em especialistas sobre nossa nação. Laborie, portanto, inicia um processo de repatriação de Denis, com o qual também concordamos e pretendemos contribuir, ainda que por outro viés.

Reavaliando a trajetória denisiana como membro de uma parcela vanguardista das letras francesas, com especial ênfase em sua vigorosa atuação na produção historiográfica da década de $1820,{ }^{12}$ intentamos demonstrar que, apesar de sua estatura menor, o autor se inseria em um projeto liberal de caráter francês, que percebe e propõe uma nova perspectiva dos fundamentos da experiência humana, como inspirada na busca e defesa da liberdade e igualdade. Esse pouco considerado liberalismo francês se destaca da corrente inglesa, com a qual dialoga, pela importância atribuída à cultura e sociedade como elementos essenciais do desenvolvimento humano. Para esses historiadores, a experiência humana assume significação ao demonstrar a luta das sociedades pelo seu desenvolvimento cultural, associado ao desenvolvimento de sua sociedade em uma comunidade de livres e iguais. ${ }^{13}$

\footnotetext{
${ }^{11}$ A autora realiza uma pesquisa de grande escopo e bem fundamentada. Sua hipótese e conclusões apresentam, porém, um equívoco que urge rever: ao considerar Denis apenas em relação à obra relacionada à ficção e história literária, dos anos 1824-1826, e principalmente, ao eleger essa pequena parcela como a mais importante de seu trabalho, a historiadora chega a conclusões sobre toda a carreira do autor, que se limita à literatura brasileira. Nesse recorte extremamente limitado, ficam de fora: dezenas de títulos, publicados ao longo de sete décadas de carreira, em que se encontram, inclusive, os títulos mais importantes do autor dentro e/ou fora da França, obras estas dedicadas à história (inclusive da literatura) e erudição.

${ }^{12}$ Dentre vários títulos publicados na década de 1820, Denis publicou histórias do Brasil, Guiana, Peru, Argentina e Chile, consagrando-se como uma referência nos temas sul-americanos.

${ }^{13} \mathrm{Na}$ pioneira formulação teórica desse movimento, pela pena de Augustin Thierry produz-se uma filosofia da história a qual postula que, uma vez que a liberdade e a igualdade fossem condições naturais e desejáveis do ser humano, a tendência natural seria a de defendê-las. Porém, como o desenvolvimento bélico "superior" de algumas "raças" (em sentido etnológico) dirigia ao confronto e à dominação de uma raça por outra - caso, por exemplo, dos Francos dominadores e dos Gauleses submissos -, deduzia ele que o motor da história seria a luta da "raça" submissa pelo fim da opressão e das regalias alcançadas pela conquista. A originalidade da teoria derivava do revisionismo com que Thierry analisa teorias formuladas pela nobreza no século XVIII, através das quais justificavam suas regalias como direitos de conquista. Ao reavaliar esse processo a "contrapelo", Thierry reverte as regalias como sinais de opressão e justifica a Revolução como uma forma de justiça histórica (Thierry, 1827).
} 
Atribuindo e buscando demonstrar, nos selvagens e antigos, a existência de um instinto natural para a liberdade - que faz deles guerreiros em sua defesa - os teóricos da historiografia liberal desenvolvem uma justificativa para a Revolução Francesa, como uma "reintegração de posse" do povo francês, de seu direito natural à liberdade e igualdade (Mellon, 1958; Gauchet, 2002). Em torno do grande problema político e social de compreender-se a Revolução Francesa, e perante o desenvolvimento de uma nova percepção do tempo recémadquirida, a historiografia francesa reconhece como motor da experiência humana a luta pela liberdade, cujos exemplos serão buscados em todos os povos e momentos, considerando-se essa teoria como universal.

Dessa maneira, separavam-se definitivamente os modernos franceses dos antigos, não só porque a liberdade atingia novos padrões, como também porque os franceses assumiam uma nova antiguidade, particular, enraizada nos gauleses. Essa diferenciação historicista manifesta-se nas letras em geral, demonstrando a certeza do esgotamento dos modelos antigos e da necessidade de substituírem-se as musas por "divindades locais". Novos gêneros literários, novas musas e tempos míticos deveriam ser recuperados, como já demonstrara o grande ícone do início do século XIX, Walter Scott, que consolidaria uma nova forma de "pintar", presentificar (e interpretar) o passado: o romance histórico. ${ }^{14}$

\section{O ESGOTAMENTO DOS ANTIGOS}

Para ilustrar a relativização e decorrente questionamento sofrido pelos antigos, citamos o prefácio do crítico literário romântico (e mentor de Ferdinand Denis) Charles Nodier. Importante membro da República das Letras nas primeiras décadas do século XIX como escritor e animador de um importante circulo literário das "Soirées de l'Arsenal", ${ }^{15} \mathrm{O}$ futuro membro da Academia Francesa de Letras representava uma importante referência da voga romântica. Além de seu círculo literário na Bibliothèque de l'Arsenal, Nodier dedicavase a pensar (e fomentar através de seu círculo) os rumos da teoria literária em formação; e sendo assim, quando um autor iniciante, Cyprien Bérard, lançou uma obra de gênero ainda experimental - o romance gótico, foi convidado a prefaciá-lo, proporcionando ao jovem autor uma referência de autoridade.

\footnotetext{
${ }^{14}$ Não há como exagerar quando se afirma a importância de Scott na historiografia romântica. Reconhecidas suas obras como narrativas legítimas de história por grande parte dos românticos franceses como Michelet e Thierry, Scott teve influência consciente na forma como Thierry e Michelet propõem fazer reviver o passado.

${ }^{15}$ Nodier conta-se entre os primeiros fomentadores do Romantismo, ao agregar importantes talentos em seus cenáculos românticos, enquanto administrava a Bibliothèque de l'Arsenal. Substitutos dos salões iluministas, estes encontros de iguais reuniam artistas, escritores, principalmente liberais e românticos, politicamente alicerçados na revolução pelas palavras, em período conturbado de censura literária, a Restauração Bourbônica (1815-1830). O grupo de Nodier foi frequentado por nomes que se tornariam posteriormente imortais, como ele mesmo, Victor Hugo, Alexandre Dumas, SainteBeuve e também Ferdinand Denis.
} 
A apresentação a Lord Rutbwen ou Les Vampires, de Nodier (1820, p. i-iv) apesar de pequena, é bastante ambiciosa e reveladora sobre o estado de ânimo do romantismo frente aos modelos clássicos. ${ }^{16} \mathrm{Nela}$, Nodier afirmaria que a inexistência do gótico entre os escritos de Aristóteles demonstrava não apenas a novidade do gênero, como também o esgotamento dos modelos clássicos. Observando ainda que formas antigas do romance: pastoral e satíricorealista haviam se esvaziado de sentido perante a experiência moderna, fazia-se necessário o surgimento de novos gêneros capazes de refletir a existência e expressar a verdade da vida contemporânea. ${ }^{17}$ Nodier destacava a necessidade de novos gêneros para novas verdades. Até mesmo o termo designativo desse gênero literário, o termo romance, apontava nessa direção: "O nome em si, romance, que lembra uma língua moderna, uma literatura moderna, uma idade moderna da imaginação e do sentimento, exclui qualquer obrigação de uma imitação servil da antiguidade" (Nodier,1820, p. i), declara. E o uso do adjetivo servil, tão próximo de uma memória da libertação recente dos servos franceses (1789), bem demonstra o tom político dessa teoria literária em formação. A literatura, como a sociedade, devia libertar-se de antigos grilhões de servidão - nesse caso, em relação à Antiguidade Clássica. ${ }^{18}$

Atentando ainda para a distância que separa os modernos franceses dos gêneros clássicos, nos quais já não podem encontrar verossimilhança, ele conclui que:

[...] deve-se buscar no romance moderno um outro tipo, no caráter atual de nossa civilização, e outra fonte de inspiração nos nossos sentimentos os mais comuns, nas nossas paixões mais pronunciadas, nas nossas superstições as mais poéticas (Nodier, 1820 , p. ii). ${ }^{19}$

\footnotetext{
${ }^{16}$ Vale lembrar que a celebridade de Nodier e alguns problemas de diagramação da obra levaram à atribuição geral da autoria a Nodier.

${ }^{17}$ Destaque-se, portanto, a noção historicista de uma ficção que deva refletir e narrar a verdade da sociedade que a produz, ou seja, do caráter documental da literatura.

${ }^{18}$ Essa fórmula, que resume o pensamento Romântico acerca da necessidade de verdades nacionais a serem narradas pela literatura, paralelamente à eleição de novas musas nacionais, retorna em Denis, quando fala sobre o Brasil. Considerada como um apelo ao pitoresco (no sentido do exotismo tropical) pela historiografia literária brasileira, essa perspectiva representa na verdade um eco, uma transposição para o Brasil, de um desejo francês que se propõe universal - a elaboração da própria antiguidade como parte da história nacional.

${ }^{19}$ Cf. a passagem completa: «La seule raison qu'on puisse faire valoir en faveur de ce choix, c'est qu'on ne connait pas de roman chez les anciens qui puisse être considéré comme modèle classique, et qu'il ne paraît pas qu'Aristote se soit occupé de tracer les règles de cette espèce de composition. Le nom même de roman qui rappelle une langue moderne, une littérature moderne, un âge moderne de l'imagination et du sentiment, exclut l'obligation de cette imitation servile de l'antiquité, condition universelle et absolue du beau dans tous les arts. Nous sommes trop loin en effet des idées naïves du premier âge pour prendre plaisir aux pastorales amours des héros de Longus, ailleurs que dans cette histoire délicieuse de Daphnis et Chloé, qui a perdu chez nous toutefois sa vraisemblance avec ses modèles. Grâce au perfectionnement de nos mœurs, le grand nombre des lecteurs ordinaires de romans repousseraient les peintures cyniques des imitateurs les plus élégants de Lucien ou de Pétrone. Si l'un de ces genres a cessé depuis longtemps d'être classique, parce qu'il a cessé d'être
} 
Nodier, portanto, exemplifica a eleição de Clio para musa única de todas as letras e artes. A arte deve dedicar-se à expressão da identidade nacional, desde sua antiguidade até o tempo corrente. Amigo e discípulo, Ferdinand Denis seguiria pelo mesmo viés, ao nos proporcionar um projeto nacional de arte e identidade, adaptado do modelo que se criava na França, por um grupo que não apenas era romântico, mas, principalmente, liberal, e, por esse viés, retornava à Antiguidade como modelo. Porém não mais para o futuro, mas para compreender e narrar o passado.

\section{Os ANTIGOS E OS SELVAGENS}

Nossa apreciação do projeto denisiano vai de encontro à perspectiva canônica brasileira para seguir pela senda esboçada em Nodier, supracitado: a da descoberta dos mitos e arquétipos nacionais. É a partir dessas premissas que se deverá rever sua proposta de uma antiguidade brasileira baseada nos indígenas, que ele assim justifica "O Brasil, que sentiu a necessidade de adotar instituições diferentes das que lhe foram impostas pela Europa, experimenta já a necessidade de ir buscar suas inspirações poéticas em uma fonte que lhe pertença realmente" (Denis, 1826, p. 515). Os característicos destaques ao imperativo da liberdade, em paralelo à proposta de ruptura com a Antiguidade Clássica e à noção de uma identidade que deve ser perseguida até a própria antiguidade, são elementos presentes no prefácio a Lord Ruthven e representam ícones do credo liberal francês, propondo-se universal e útil à nação recém-independente, através do Résumé de l'bistoire littéraire du Brésil de 1826.

O Brasil, que acabara de se tornar independente, necessitava também libertar suas letras. Denis concluiria que "se essa parte da América adotou uma linguagem que aperfeiçoou nossa velha Europa, deve também rejeitar as ideias mitológicas devidas às fábulas da Grécia” (Denis, 1826, p. 515). Esse clamor ultrapassa a mera perspectiva de um chamado ao pitoresco, à cor local: ${ }^{20} \mathrm{O}$ conceito de liberdade tem uma carga semântica muito forte na França pósrevolucionária, para que fosse usado de forma ligeira. Denis entende que, no caso brasileiro, a mitologia grega não estava em harmonia "com o clima, nem com a natureza, nem as

vrai; si l'autre n'a jamais été classique pour les honnêtes gens, parce qu'il n'a jamais été moral, il faut chercher au roman moderne un autre type dans le caractère actuel de notre civilisation, et une autre source d'inspiration dans nos sentiments les plus habituels, dans nos passions les plus prononcées, dans nos superstitions les plus poétiques.» (Nodier, 1820, p. i-ii).

${ }^{20}$ Os conceitos de pitoresco e cor local vêm sendo revisitados por autores como Temístocles Cezar (2004) que, ao contextualizá-los, dá nova interpretação que vai bem além das formas atuais de exotismo e apelo aos sentidos. Cezar nos esclarece que pitoresco e cor local remeteriam à visualidade da narrativa histórica romântica, sua necessidade de tornar-se sensorial para melhor ser memorizada, e também para que o apelo fosse maior. Quanto à sensorialidade da narrativa romântica, já destacada como um valor por Thierry (1827), é importante destacar o trabalho de Marcelo Rangel (2011), cuja tese demonstra esse aspecto no romantismo brasileiro. Cito ainda o artigo de Regina Zilberman "“Cor local' e história literária” (2014), em que a autora trata desse conceito na perspectiva da história da literatura, concluindo em sentido próximo ao apresentado por Cezar, acima. 
tradições do Brasil" (Denis, 1826, p. 516); lembremo-nos de que à conclusão semelhante chegara Nodier, seis anos antes.

Ressalta-se também o apelo às tradições, aí presente, à recuperação cultural, que ultrapassa a paisagem e indica principalmente a atuação humana. Mas não é aos portugueses que ele se refere; como também na França, tratava-se dos gauleses. Novamente, havia que mudar a direção do olhar, pois o Romantismo que acusa a Musa grega de inverossímil para os modernos não é apenas estético, mas também político. Pretende não apenas romper com um passado alheio, mas também com uma herança histórica elitista.

Essa nova musa deve cantar os vencidos da história, as origens heroicas de seu povo, e suas origens recuadas no passado: como proclamara Augustin Thierry, arauto da historiografia liberal. ${ }^{21}$ Em consonância, Denis nos propõe que também encontremos nossos antepassados míticos, os indígenas (e alguns negros), em cuja alma se encontra um "ardor que é todo pela independência, e pela liberdade das florestas" (Denis, 1826, p. 523). Tão heroicos quanto os antigos, eles deveriam representar o mesmo papel nas fábulas da Nação:

Seu tempo de fábulas misteriosas e poéticas serão os séculos em que viveram os povos que aniquilamos, os quais nos espantam por sua coragem ... a lembrança de sua grandeza selvagem preencherá a alma de confiança, suas crenças religiosas animarão os desertos; os cantos poéticos, conservados por algumas nações, embelezarão as florestas. O maravilhoso, tão necessário à poesia, se encontrará nos antigos costumes desses povos ... que teriam eles de inferior aos tempos fabulosos da Grécia, esses homens a quem não se pode arrancar uma queixa em meio a horríveis suplícios, e que pediam a seus inimigos que renovassem os tormentos, para que assim fosse maior sua glória? (Denis, 1826, p. 515-7)

A cisão com os Antigos não se dá apenas de forma geográfica, mas, novamente, política. Pois os gregos e romanos, cujas narrativas se escandiam para justificar miticamente as origens de reis europeus que se consideravam herdeiros ora de gregos, ora de troianos, ou

\footnotetext{
${ }^{21}$ Em 1820, como colaborador do periódico liberal Courrier Français, Augustin Thierry lança em dez artigos de crítica historiográfica (as Lettres sur l'bistoire de France, 1827) seu libelo sobre a nova história que se deveria escrever; ao criticar a história tal como se escrevia em seus dias como áulica e mentirosa, propõe que se leiam os documentos a contrapelo, erigindo por monumento a herança cultural popular e escrevendo-se uma narrativa que tematizaria a nação e seu desenvolvimento sociocultural. Em 1827 essas cartas tornam-se um livro em que são acrescidas de mais quinze e assumem, então, o papel oficial de primeiro texto teórico sobre a historiografia liberal francesa. As "Lettres" tiveram um papel crucial no desenvolvimento dessa nova vertente, plural em suas formas e em seu pensamento, mas sem dúvida alguma, inovadora (Reizov, 1962; Gauchet, 2002). Ferdinand Denis era também membro do Courrier e, portanto, do grupo liberal, o que reafirma nossa concepção de sua adesão ao projeto de Thierry. Seguindo autores como Mellon e Gauchet, podemos considerar essa relação natural, uma vez que os anos 1820 na França teriam transformado a imprensa em um campo de batalha política em que se estava ou ao lado do Rei (conservadores) ou em defesa da Revolução (liberais) (Mellon, 1958).
} 
de romanos, não poderiam servir à nação de vítimas desses mesmos invasores, cujos herdeiros haviam conquistado e oprimido os ascendentes gauleses na França, e indígenas, no Brasil. Nesse processo, em que a relação com o passado e sua narrativa se transforma através de deslocamentos temporais e semânticos, a Antiguidade Clássica sofrera um distanciamento em que se tornara uma "outridade" em relação ao presente. Por outro lado, esse deslocamento, em seu sentido ontológico, faz dela a referência de análise das várias "antiguidades nacionais" a serem (re)construídas pelas histórias nacionais e suas origens diversas. Cada nação - descobriam os românticos - possuía sua própria antiguidade, desconhecida, porque velada, escondida sob a narrativa dos vencedores. Seu (re)conhecimento se daria a partir da remodelação de metodologias e perspectivas já presentes nos estudos clássicos, a serem adaptadas aos "novos antigos".

Reconhecendo essa universalidade, Denis nos propõe uma forma de acesso ao passado nacional herdada da experiência dos estudos da Antiguidade:

Que sejam estudadas as frágeis tribos que escaparam a três séculos de destruição, e aí veremos ainda todos os pensamentos primitivos que excitam fortemente a imaginação; mas, para encontrá-los em toda a sua energia, não se deve buscá-los nos povoados que a civilização destruiu lentamente e que guardam os males da raça americana nas paragens a que foram confinados: deve-se penetrar no seio das florestas, interrogar as nações livres... (Denis, 1826, p. 518)

Vê-se que a etnologia e filologia a serem usadas no resgate dos antigos europeus também serviam de acesso ao passado indígena. A experiência de estudo dos costumes e da língua, o acesso ao passado através de uma abordagem etnográfica e filológica, uma "arqueologia" linguística necessária ao acesso de povos ágrafos e sem monumentos conhecidos, todos estes fatores se encontram propostos tanto para a compreensão do passado francês, como iam sendo reelaborados entre os países centro-europeus (Vermeulen, 2006) e serviriam, acreditava o erudito, para que se pudesse reconstruir a história do Brasil.

Como credo principal, encontrava-se a certeza desses teóricos de que, em todos os tempos e lugares, havia memórias de guerreiros do passado, cuja luta pela autonomia e pelos direitos essenciais do ser humano, liberdade e igualdade, seria sempre a culminância de sua história. Nesse projeto, cuja originalidade ultrapassa as questões formais, o historiador abandona o nível metafórico para estabelecer uma comparação de equivalência entre antigos e selvagens, cuja aproximação se justifica principalmente pela igualdade com que eles lutam em defesa do bem maior da humanidade: a liberdade.

\section{ENTRE O BIOGRÁfico E O ROMANESCO: ACENOS À ANTIGUIDADE}

Por outro viés, há continuidades importantes nessas narrativas que extrapolam o desejo romântico da originalidade e do abandono dos modelos da Antiguidade. Pela abordagem de outros gêneros verificar-se-á como essa utilização da Antiguidade é instrumental para pensar a história e a literatura nas Américas e, em especial, no Brasil. Há, 
não obstante, modalizações na categorização e nas formalizações propostas consoante o gênero de discurso empregado, ou seja, nos relatos autobiográficos, representados pelas cartas e diários, nos relatos de caráter mais histórico e etnográfico e nas narrativas romanescas, as interpretações dos eventos históricos, as descrições e análise das espécies vegetais, animais e minerais, a exposição e avaliação dos costumes dos vários povos, assim como a comparação com a Antiguidade greco-romana são configuradas, a despeito das similaridades das apresentações, segundo o ethos peculiar de cada gênero discursivo.

Essa diferença de tom pode ser comprovada, por exemplo, pela simples comparação entre as cartas e o diário de Denis no período de 1816-1819 e a obra de 1824, Scènes de la nature sous les tropiques et de leur influence sur la poésie. ${ }^{23}$ Em seus diários e em suas cartas, datadas de sua estada no Brasil entre 1816 e 1819, a persona biográfica de Denis (ainda que ele pontue sua admiração pela exuberância da flora e da fauna brasileiras) se constrói por um sentimento de desalento progressivo, de uma personalidade não adaptada à realidade local, somado à infelicidade do insucesso financeiro e das tentativas frustradas de adquirir fortuna. No diário Mes sottises quotidiennes, numa anotação de 04 de dezembro de 1818, Denis relata seu arrependimento de não ter ido à Índia e ter ficado no Brasil, pois inicialmente sua ideia era reunir-se com seu amigo Adolphe Dubois em Bengala (depois instalado em Calcutá), o Brasil então não representando senão uma escala nesse percurso até as Índias (Bourdon, 1958, p. 279). ${ }^{24}$

O jovem Denis se relacionava, majoritariamente, com franceses que residiam no Brasil ou que estavam em viagem pelo país. Seu microcosmo social, uma imagem bastante apagada do contexto de soirées, reuniões sociais e bailes da sociedade francesa, se reduzia basicamente à casa da família Procópio, de que a matriarca, uma senhora francesa, havia se casado em segundas núpcias com José Procópio de Castro. Esta senhora tinha três filhas, Clarisse, Joséphine e Iphigénie, e um filho, Adolph. É com essas três (mormente com Clarisse e ulteriormente com Iphigénie) e com a senhora Procópio que as relações e os sentimentos do jovem Ferdinand Denis vão se incrementar e estreitar, variando desde a amizade filial às paixões juvenis. Segundo o que é reportado pelo próprio autor, sua condição financeira lhe embargava o acesso às casas da elite local. De qualquer forma, sua aproximação às pessoas do lugar se revestia do distanciamento etnográfico que não se furtava a registrar, com profunda admiração, o modo de vida e os costumes de algumas tribos indígenas, a exemplo dos maxacalis e botocudos, e cenas do quotidiano, como na narrativa acerca de um africano, descrito como um Orfeu negro a tocar seu instrumento de cordas improvisado. Os caboclos lhe pareciam todos miseráveis, assim como miserável seria a situação da maior parte dos indígenas, arrojados a um processo de forçada aculturação.

É emblemática a forma com que avaliava os variados eventos do quotidiano e as cenas do contexto sociocultural brasileiro ao qual teve acesso. Numa carta ( $\left.\mathrm{n}^{\mathrm{o}} 13\right)$ de setembro de 1817, faz ele sua apreciação de uma encenação no Teatro de São João na Bahia, intitulada

\footnotetext{
${ }^{22}$ Bourdon, 1958.

${ }^{23}$ Denis, 1824.

${ }^{24}$ Cf. também Carta 26 (Bourdon, 1958, p. 241) e Carta 35 (Bourdon, 1958, p. 253).
} 
"Sacrifício de Ifigênia", o que se torna mais relevante para o nosso argumento em vista de se tratar de uma referência precisa à Antiguidade Clássica. A passagem é cheia de humor, em que Denis não desmerece uma verve genuinamente irônica, beirando o sarcasmo. ${ }^{25}$ É também um depoimento precioso sobre a presença de negros e negras na cena teatral brasileira em Salvador no início do século XIX, ainda que com termos desqualificadores e depreciativos. Ele chama a atenção principalmente para o figurino dos atores e adereços de cena como completamente destoantes do contex to histórico greco a que competiria remontar e imitar: Calcas, por exemplo, vestia um figurino de mágico e um gorro de rabino, enquanto Agamêmnon portava um sabre à hussarda. Todavia, o maior absurdo para o nosso autor foi a transgressão da narrativa mítica:

Os guardas, barrete militar na cabeça, circundam o altar, e o sacrifício está para começar, quando o Sr. Aquiles, não sei por que razão, chega com alguns negros, bota para correr os encarregados do sacrifício, enfia seu acendedor sob o ombro do desafortunado Calcas e vem prestar saudações ao público. Esta é, sem exagero, a maneira com que se encena a tragédia na Bahia, a segunda cidade do Brasil (Bourdon, 1958, p. 210/Carta 13).

É certo que Denis não deixa de elogiar certos entrechos dramáticos por sua parte musical, que poderiam ser condizentes, segundo a letra do texto, ao caráter cômico do vaudeville, mas, ao mesmo tempo, chama as danças aí correlatas de detestáveis: ele exemplifica com o lundu, cuja execução manifestaria uma boa qualidade técnica, porém, a indecência da dança exorbitaria do senso de decoro de um jovem europeu do XIX.

Não obstante, a música ao par da dança são qualidades que ele atribui à natureza do elemento africano no Brasil: a "música exerce todo seu domínio sobre os negros; eles são músicos por instinto” (Bourdon, 1958, p. 223/Carta 18). Nessa carta a seu irmão, ele conta sobre um estivador que fez seu instrumento com uma casca de tartaruga tendo uma única corda, analogia que lhe remete à figura de Orfeu. Este Orfeu negro, segundo as palavras de Denis, com sua lira e entoando cantos, atrai uma audiência animada e Denis, embora não entendendo as canções em língua africana, aufere daí uma experiência estética e emotiva singular e extremamente aprazível, de certo modo, equivalente à poesia lírica e elegíaca grega, equivalência cuja remissão é muito recorrente em Scènes de la nature sous les tropiques et de leur influence sur la poésie. ${ }^{26}$

Ferdinand Denis parece resguardar a si e a sua identidade francesa no trato com as letras, na experiência de leitura (dos livros que encontra na biblioteca e das cartas) e da

\footnotetext{
${ }^{25}$ Não menos irônicas são suas observações sobre os autos realizados dentro da igreja por monges e clérigos, cujo efeito a um europeu não poderia ser senão a sensação de hilaridade e ridículo, e que, mesmo assim, segundo seu testemunho, ocasionava aplausos de uma plateia que se comportava como se estivesse num teatro (Bourdon, 1958, p. 237/Carta 24).

${ }^{26}$ Nessa mesma obra (Denis, 1824, p. 224), o autor repete o mesmo relato sobre este Orfeu negro.
} 
escrita ${ }^{27}$ cujo diário e cujas cartas para amigos e familiares testemunham. ${ }^{28} \mathrm{~A}$ alteridade desse Brasil de florestas e desertos, de rios e Atlântico, sem deixar de marcar profundamente a pele e o imaginário do jovem Denis, lhe manifesta sua faceta agreste, indomável e, segundo ele próprio, provocadora das mais intensas emoções que uma natureza juvenil não conseguiria expressar. De uma forma ou de outra, o gosto da época pelas ciências naturais, pela botânica e pela mineralogia, que ele compartilha com o pai em suas cartas, faz com que persevere na experiência, observação e registro dos fenômenos e achados que considera importantes. $\mathrm{O}$ jovem Denis desfruta então do nado, para aliviar um calor causticante; se dedica com seus amigos da mesma idade, Grain e Pallus, à caça e, por conseguinte, ao empalhamento de pássaros. Essa técnica de empalhamento ${ }^{29}$ era uma das atividades mais prazerosas (e a mais rentável) para nosso autor que, paulatinamente, soube aprimorar e, assim, garantir um certo subsídio para a família em Paris, para a qual enviava as espécimes, tanto aves de vários tipos, como borboletas e insetos variados. ${ }^{30}$

Em 22 de junho de 1819, em carta $^{31}$ para o pai, nosso jovem escritor fala de seu projeto de uma missão ao rio Jequitinhonha em busca de angariar alguma fortuna. É uma oportunidade para fazer e tomar notas: "Elas terão por objeto, em geral, as produções naturais e os costumes dos índios, aí incluindo informações geográficas que conseguirei obter, e as várias palavras da língua dos botocudos que poderei descrever com nossos caracteres". A expedição, ao final, se revelaria um completo fracasso, porém, tal experiência, assim como todas as notas e informações registradas, marcará ulteriormente o percurso a ser trilhado pelo jovem escritor em suas inúmeras obras subsequentes.

Ao contrário do clima de desalento que permeia seus escritos autobiográficos desse período, sua obra de 1824, Scènes de la nature sous les tropiques et de leur influence sur la poésie, é perpassada, em sua maior parte, por um sentimento de euforia marcadamente expresso pelo narrador. Entre uma obra e outra, além da temática de fundo relativa ao princípio da liberdade dos povos, temática essa que revém à tona em alguns momentos da narrativa de Scènes, uma dicção, por assim dizer dramática, e uma espécie de teatralização dos eventos narrados e/ou

\footnotetext{
${ }^{27}$ Além disso, em seu diário, Denis relata que traduziu diálogos de uma obra de Caroline-StéphanieFélicité, Madame de Genlis (Bourdon, 1958, p. 228/Carta 20).

${ }^{28}$ Numa carta para sua mãe (Bourdon, 1958, p. 233-234/Carta 23), ele fala como se imaginasse na casa dos pais em Paris, assim como as ações corriqueiras dos familiares e de seu amigo, o pintor Arsenne, numa espécie de exercício espiritual em que esquecia estar na Bahia. Cf. também Carta 36 (Bourdon, 1958, p. 254-5).

${ }^{29}$ Cf. Carta 40 (Bourdon, 1958, p. 261-2).

${ }^{30}$ Para Denis, a atuação como entomologista (naturalista) representava uma atividade erudita e, portanto, à altura de sua pessoa de letrado, ao contrário de atividades consideradas menores, a exemplo da função no comércio de retalho, que recusa de maneira ofendida, quando oferecida pelo então cônsul, M. Berthon, em 1819 (Bourdon, 1958). É nesse momento que, como naturalista/ grosso comerciante, ele se dirige à aventura pelo Jequitinhonha, que inspiraria tantas de suas obras, marcadamente Scènes, de 1824 (Denis, 1819).

${ }^{31}$ Bourdon, 1958, p. 262-3/Carta 41.
} 
vivenciados singularizam o estilo do escritor em início de carreira. Segundo Jawad Daheur e Elisabeth Hamm, ${ }^{32}$ houve uma mudança na apreensão estético-literária da natureza, cujo foco passava da paisagem pastoral e do campo cultivado e dominado pelo homem para a floresta e para a paisagem natural mais selvagem. Essa "encenação da natureza" caracterizaria boa parte da produção escrita de Denis, num esforço teórico original para distinguir e formalizar em parâmetros formais a literatura de países, a exemplo do Brasil, que deixavam a posição de colônias. Assim como a paisagem do Rio de Janeiro e, mormente, da Bahia e de Minas ambientava a ação discursiva e efetiva do autor de Mes sottises quotidiennes e das cartas, assim também em Scènes o espaço e os fenômenos da natureza compõem, ao mesmo tempo, cenário e níveis de interlocução com o narrador. Vejamos uma passagem desse tipo de concepção:

Poemas, dramas, espécies de elegias, mitos nos quais as cenas da natureza costumam ser adjudicadas, concebem uma idéia bastante vantajosa da genialidade poética desses povos e de sua facilidade em fazer comparações (Denis, 1824, p. 392-3).

A comparação aqui é feita com a literatura javanesa, mas esse é um procedimento geral ao longo da obra. De um lado, a paisagem natural de caráter mais selvagem é exaltada, configurando essa encenação da natureza; de outro, há uma comparação a título de equivalência entre a produção artística e literária dos vários povos que estão sob os trópicos com a cultura e a literatura gregas. Em várias ocorrências textuais, essa busca de equivalências recai numa fórmula simples de remissão ao duplo legado de Grécia e Roma. De forma similar, o épico indiano Ramayana é comparado às mais belas criações da Antiguidade, assim como Lakshmi seria a Vênus correlata dos indianos e o deus Indra conservaria todos os atributos de Júpiter (Denis, 1824, p. 382, 389). Além dessa referência constante às ficções gregas, segundo a letra do texto, nosso jovem escritor não se furta a falar de Apuleio, do mito de Eros e Psykhé e de aspectos da doutrina de Platão e Pitágoras aí inseridos, nessa abordagem da literatura indiana. Não obstante, depois da travessia do cabo da Boa Esperança, a poesia dramática portuguesa, ao par das peças latinas, poderia ter sofrido, segundo o argumento denisiano aí explorado, a influência dos dramas indianos: é o espetáculo do espaço natural magnífico dessas regiões, franqueado pelas navegações, que transformaria e caracterizaria a produção e recepção de obras dramáticas e literárias, levando nosso autor a citar em seu afã erudito a incrível narrativa dramática de Kalidasa, conhecida como Xacuntalá (Denis, 1824, p. 368-369).33

Não obstante, o foco do escritor em Scènes não é em obras literárias de um gênero já consolidado e tradicional. Embora faça referência ao poema épico Caramuru, sua concepção de poesia, em particular, e de literatura, em geral, se amplia para abrigar cantos e hinos de indígenas e demais autóctones das várias regiões constantes em seu périplo; de certo modo, também assimila os relatos de viajantes, anônimos ou escritores de livros. Ele fala de uma

\footnotetext{
${ }^{32}$ Daheur; Hamm, 2019.

${ }^{33}$ Cf. Fonseca, 1993, p. 61-85.
} 
literatura potencial, que dará seus frutos apenas no futuro, por exemplo, quando prenuncia que Brasil e Peru vão fornecer ulteriormente modelos de poesia (p. 79) ou quando augura uma nova Mênfis que despontará entre os rios da Amazônia (p. 96)! É, ao mesmo tempo, uma aposta e um manifesto literário, em que traça as linhas e os parâmetros gerais, pautados nessa formalização mais genérica concernente à encenação da natureza. Acoplada a isso está sua estratégia de remissão ao legado cultural grego que lhe serve de pedra de toque: se o "clima e o aspecto da natureza têm uma influência direta sobre as inspirações poéticas", busca-se a analogia com o "céu da Grécia e da Itália", a partir de que se produziram suas obras-primas (p. 2); a poesia presente nos mitos e histórias tristes dos indígenas é comparada às elegias mais angustiantes (p. 98); os africanos e indígenas são poetas e músicos de um talento inato, cujo entusiasmo é inspirado pela Musa-natureza (p. 85); as Amazonas constituiriam um mito amazônico criado às expensas do mito grego (p. 101-103). Dessa forma, a Grécia, em primeiro plano, e Roma, em segundo, são instrumentais para uma valoração positiva dessa produção literária nascente e a nascer, o que o faz se munir de inúmeras referências a figuras históricas e míticas da Antiguidade, como, por exemplo, Teócrito (a que Camões é comparado - p. 37), náiades, tritões, o dragão do jardim das Hespérides, Plínio, Estrabão, entre outros.

Como dito anteriormente, a temática da liberdade e os princípios que lhe são correlatos permeiam as ideias e escritos de Ferdinand Denis dentro de um quadro mais geral dos pensadores franceses de sua época. E esse aspecto se configura como um dos principais vértices de duas apostas literárias do jovem escritor: Scènes de la nature sous les tropiques et de leur influence sur la poésie abriga em si duas narrativas romanescas, uma centrada na figura indígena de Kumuraí (Koumourahy, segundo a grafia do autor), a outra na figura de Zumbi. Se a primeira Bourdon chama de novela (1958, p. 127, n. 3), talvez por sua extensão menor (64 páginas), a segunda narrativa trata de uma personagem histórica, Zumbi dos Palmares, cuja vida se romanceia em uma espécie de romance biográfico, que se estende sobre 10 capítulos do livro, em uma centena de páginas. O narrador nas duas narrativas advoga explicitamente a liberdade para o indígena e para o negro, respectivamente, enquanto denuncia as mazelas da escravidão (e condena a violência da conquista portuguesa), chamando a atenção para a condição miserável dos escravos, assim como dos povos indígenas, que foram ou dizimados ou sofreram um processo forçado de aculturação. ${ }^{34}$ Por outro lado, o autor escolhe aventuras e heróis em que a liberdade ocorre a partir da iniciativa dos cativos, cujo anseio pela autonomia vem naturalmente se amalgamar na nacionalidade brasileira, pela associação entre as raças.

É interessante notar, no primeiro caso, o argumento utilizado para a passagem de um discurso de caráter mais histórico e etnográfico para outro francamente ficcional: apelando para um momento de sua própria vida, a viagem de retorno do Brasil para a França, Denis teria encontrado um jovem português que lhe teria feito o relato de um chefe indígena, cuja

\footnotetext{
${ }^{34}$ A escolha desses dois personagens não pode ser ocasional. Tanto o indígena Maxacali quanto o negro africano representam personagens que lutam contra a opressão invasora dos portugueses para resgatarem sua liberdade e autonomia. Seu papel, portanto, de ícones da liberdade intrínseca aos brasileiros não pode ser minimizado.
} 
leitura ele faz a seguir. Em termos gerais, Kumuraí é filho do chefe da tribo dos Maxacalis, Vapubassu, o qual se ressente do contato dos portugueses com os integrantes de sua tribo e prefere entregar seu filho para ser criado pelos conquistadores portugueses. Dessa forma, Kumuraí é um ser entre dois mundos, cujo apelo da floresta vai ser predominante para conclusão de sua trajetória, a opção pelo modo de vida selvagem (autônoma); mas sua angústia existencial é patente em seus discursos e ações, angústia essa que vai ser extremamente incrementada por sua paixão pela filha do comendador, Helena.

Talvez não seja à toa a escolha do nome da heroína: enquanto a Helena grega teria ocasionado a destruição de gregos e troianos, esta outra destruirá as ilusões e o coração de Kumuraí. Dentro de uma ambientação romântica, o herói pautará sua existência e suas emoções pela paixão cega que o faz transpor os mais terríveis obstáculos naturais e enfrentar inúmeros embates. O melancólico herói não conseguirá o seu intento, ainda que, ao final, Helena também se mostre apaixonada por ele. Restam ao desalentado Kumuraí uma existência penosa e errante, as últimas palavras de sua amada transmitidas por carta e sua história contada ao amigo português, posta em escrito por nosso autor.

Quanto ao outro relato, já na primeira referência a Palmares, mencionam-se as dores dos vencidos e os crimes dos vencedores, uma visão de ruínas que evoca no narrador cenas similares de Roma e de Atenas (p. 239). Segundo o argumento da narrativa, um negro idoso, em sua cabana isolada, desfruta de uma solidão apenas burlada pela visita de um jovem europeu que costuma acompanhá-lo na caça. Num dia em que o velho, chamado de João, se dispõe a visitar o sítio de Palmares, o jovem começa a inquiri-lo sobre o assunto, o que dá margem para a narrativa subsequente. Nesse momento, se dá a incrível revelação inicial: João não é nada menos que o filho de Zumbi, o grande líder de homens e mulheres que viviam em Palmares. Da mesma forma que na narrativa sobre Kumuraí, a paixão amorosa vai ser o motor da dinâmica romanesca: no caso, através da busca incessante e vã de Zara, por quem estava apaixonado, a qual era a filha de um chefe de tribo na África, aprisionada e trazida como escrava ao Brasil. Em nota, Denis arrola alguns historiadores que escreveram sobre Palmares, entre eles, Rocha Pitta, Southey, Beauchamp e Ayrès de Cazal (p. 246); isso não o impede de preferir uma narrativa francamente ficcional que faz a personagem do herói Zumbi dizer: "Que me importa a liberdade se não puder salvar aquela que eu amo?" (p. 249). De certo modo, sua paixão e busca incessante por Zara parece simbolizar a própria busca pela liberdade, que é a tônica do relato.

A partir de vários tópicos (escravidão, navegação, chegada, festa, fuga, juramento, guerra, sacrifício), explora-se um esquema biográfico bastante genérico e cria-se uma narrativa peculiar, de certa forma similar ao romance biográfico na Antiguidade, a exemplo do Romance de Alexandre, comentado amplamente na primeira parte deste dossiê, e do Romance de Esopo. Assim como nestes dois romances, aqui são expressas ideias filosóficas, preceitos éticos e toda uma carga ideológica, que modalizam as ações de Zumbi e as batalhas travadas por eles e seus companheiros. A liberdade que se consubstancia melancolicamente num negro liberto, no velho João, filho de nosso herói, movimenta a narrativa como um todo, ao lado da paixão amorosa que a intensifica. O herói, certamente, morre ao final: Palmares é dizimada, seu 
amor com Zara não é consumado. ${ }^{35}$ Num último gesto, Zumbi escolhe como companheira sua amiga Mery, escrava e depois liberta, que desde o início lhe dedicara o seu amor. Dessa união nascerá João, o nosso solitário e melancólico narrador, filho de Zumbi.

Tanto uma quanto a outra narrativa constituem uma aposta literária de Denis, como também uma narrativa histórica, no sentido legítimo que lhe atribui o Romantismo (ver nota 4). Elas buscam desenvolver o que se formaliza no restante da obra como "natureza encenada", ${ }^{36}$ cuja abordagem não se restringe a um paisagismo ou descrições etnográficas, mas intenta, a despeito de certa falta de destreza no estilo de narrar, apresentar personagens, ambientação de cenas e dinâmica narrativa engolfados nesse impulso renovador inspirado pela Musa-natureza.

Consoante a isso, é desenvolvida sua agenda programática concernente à teoria liberal de verniz francês: os heróis, Kumuraí e Zumbi, são personagens emblemáticos dessa visão de mundo, guerreiros da liberdade, que lutam contra a escravidão e lideram seu povo para alcançar uma equanimidade de direitos de indivíduos livres. Como instrumento da agenda liberal, as produções artísticas desses povos, seus cantos e danças, seus costumes e regras morais recebem uma valorização pela analogia e comparação (e mesmo equiparação) com a literatura, a escultura, os monumentos e outros artefatos culturais de Grécia e Itália, de gregos e romanos, com os quais indígenas, africanos e autóctones de outras terras são equiparados.

Como condizentes ao ideário romântico, as ações dos protagonistas são norteadas e justificadas pelo sentimento amoroso: ${ }^{37}$ os heróis e heroínas são acometidos pela paixão amorosa, a qual se interpõe a, como no caso de Helena e Kumuraí, ou intensifica, como na relação de Zara e Zumbi, seus projetos de autonomia e liberdade.

\section{ConClusão}

O percurso deste trabalho seguiu um itinerário de ideias de Ferdinand Denis em um recorte de obras (a maioria tratando do Brasil) datadas do período de 1810-1820; algumas de cariz mais histórico e etnográfico, a exemplo do Résumé de l'bistoire du Brésil e o Résumé de l'bistoire littéraire du Brésil, outras em que vários gêneros literários se manifestam: desde o viés

\footnotetext{
${ }^{35}$ Vale destacar que a narrativa heroica nacional mantém o caráter pedagógico da Antiguidade. O fato de as ficções históricas, em que são apresentadas as biografias exemplares de um índio e um negro, se equipararem ao bíos de Alexandre Magno, demonstra o nivelamento romântico entre heróis antigos e as re-descobertas contemporâneas, num nivelamento bastante sintomático. Mesmo assim, será curioso perceber que o sangue "azul" desses selvagens, ou seja, sua estirpe nobre entre os seus, mantém, por outro lado, a tradição heroica clássica.

${ }^{36}$ E para Denis a natureza é não apenas cenário, mas também monumento-documento: a natureza é um ícone de passado, um indício do estágio de desenvolvimento (ou não) da civilização brasileira no século XIX.

${ }^{37}$ Não se pode esquecer, igualmente, o quanto o amor romântico poderia assumir feições sociopolíticas de vanguarda em sociedades nas quais o casamento era antes de tudo um negócio ou uma aliança política.
} 
autobiográfico e memorialístico, como as cartas e diário do período de 1816 a 1819, passando ao caráter paisagístico/literário de Scènes de la nature sous les tropiques et de leur influence sur la poésie.

O objetivo mais imediato foi reintegrar Denis no contexto propriamente francês, de seu ideário sociocultural, o qual transformava e modalizava o discurso do historiador; destacam-se a contribuição de disciplinas como a arqueologia, etnografia e da filologia instrumentalizadas para configurar uma concepção da Antiguidade distanciada do momento presente, sublinhado em sua originalidade e em sua diferença para com o passado, ávido de novas noções de antiguidade, calcadas em identidades nacionais. As rupturas e continuidades características de seu tempo demonstram-se presentes e de maneira particularmente trabalhadas no projeto denisiano de uma história do Brasil.

De forma peculiar, uma certa negação dos antigos e, ao mesmo tempo, uma necessidade de mencioná-los em momentos-chave de seus textos, denunciam a estratégia denisiana de buscar uma equivalência entre antigos e determinados povos considerados na "infância" da história, cuja produção artística e cultural de um modo mais geral seria valorativamente equiparada com aquela, passada e prestigiada, de Grécia e Itália, de Atenas e Roma.

Considerando a cultura e a sociedade como elementos essenciais e intrínsecos ao modo de vida e à mentalidade dos povos, e como monumentos populares revestidos de importante função documental, Ferdinand Denis, seguindo a linha da historiografia liberal francesa, expõe em seus textos mais teóricos e representa nos personagens em narrativas romanescas um anseio comum pela busca de igualdade e liberdade, bem como a riqueza da literatura e manifestações culturais como lugares de memória nacional.

\section{REFERÊNCIAS}

\section{Fontes}

ASSEMBLÉE NATIONALE (France). Amaranthe, Alphonse, Dugommier Denis. Disponível em: http://www.assembleenationale.fr/sycomore/fiche.asp?num_dept=17494. Acesso em: 20 jan. 2016.

BEAUCHAMP, Alphonse de. Histoire du Brésil: depuis sa découverte en 1500 jusqu'en 1810. Paris: A. Eymery, 1810.

BOURDON, Léon. Lettres familières et fragments du journal intime de Ferdinand Denis à Bahia (1816-1819). Brasilia, n. 10, p. 143-286, 1958.

DENIS, Ferdinand. Journal (1829-1848). Introd. et des notes par Pierre Moreau. Fribourg: Université de Fribourg, 1932. (Collectanea Friburgensia, 30).

DENIS, Ferdinand. Journal de mon voyage au Jequitinhonha. Présentation, transcription, notes et annexes de Georges Orsoni. 2018. Disponível em: https:/ / hal-univ-paris3.archives-ouvertes. fr/hal-01568782. Acesso em: 15 mar. 2020. 
DENIS, Ferdinand. La Guyane, ou histoire, mours, usages et costumes des habitans de cette partie de l'Amérique. Paris: Nepveu, 1823. 2 v.

DENIS, Ferdinand. Le Brabme voyageur, ou la sagesse populaire de toutes les nations; précédé d'un essai sur la philosophie de Sancho, par Ferdinand Denis. A bon entendeur salut. Paris: Abel Ledoux, 1834.

DENIS, Ferdinand. Résumé de l'bistoire du Brésil, suivi du résumé de l'bistoire de la Guianne. Paris: Lecointe et Duray, 1825.

DENIS, Ferdinand. Résumé de l'bistoire de Buenos Aires, du Paraguay, et des provinces de la Plata, suivi du résumé de l'histoire du Chili. Paris: Lecointe et Duray, 1827.

DENIS, Ferdinand. Résumé de l'bistoire littéraire du Portugal, suivi du résumé de l'histoire littéraire du Brésil. Paris: Lecointe et Duray, 1826.

DENIS, Ferdinand. Scènes de la nature sous les tropiques, et leur influence sur la poesie suivies de Camoes et Joze Indio. Paris: Louis Janet, 1824.

DENIS, Ferdinand; TAUNAY, Hippolyte. Le Brésil, ou, Histoire, maurs, usages et coutumes des habitans de ce royaume. Paris: Nepveu, 1822. 6 v. (Passage des Panoramas, 26)

DÓRIA, Luiz Gastão d'Escragnolle. Um amigo do Brasil - Ferdinand Denis. Revista do Instituto Histórico e Geográfico Brasileiro, t. 75, v. 125, p. 217-230, 1912.

JOURNAL DES SAVANTS. Paris: Imprimerie Royale, janv. 1825.

JOURNAL DES SAVANTS. Paris: Imprimerie Royale, janv. 1833.

LEFRANC, Émile. Histoire élémentaire et critique de la littérature. Paris: Librairie Classique de Perisse Frères, 1841.

NODIER, Charles. Observations préliminaires. In: BÉRARD, Cyprien. Lord Ruthwen, ou les Vampires. Paris: Ladvocat, 1820, p. i-iv.

OUTREPONT, Charles Thomas F. Dialogue III, Napoléon Bonaparte et Botocoudo, Sauvage du Brésil. In: Oeuvres de Charles d'Outrepont. Paris: Firmin Didot Fréres, 1831. t. 1, p. 16-27.

PIMENTEL, Alberto. Ferdinand Denis. In: Figuras Humanas. Lisboa: Antonio Maria Pereira Livraria Editora, 1905, p. 15-21.

RICHER, Ed. Scènes de la nature sous les tropiques, et leur influence sur la poésie suivies de Camoes et Joze Indio par Ferdinand Denis. Le Lycée armoricain, v. 6, p. 555-65, 1825.

SOUTHEY, Robert. History of Brazil. London: Longman, Hurst, Rees and Orme, Paternosterrow, $1810-1819.3 \mathrm{v}$.

SOUZA E SILVA, Joaquim Norberto de. Atas das sessões de 1890. Revista Trimensal do Instituto Histórico e Geográfico Brasileiro, Rio de Janeiro, n. 53, v. 2, p. 474-7, 1890. 
THE LITERARY chronicle for the year of 1825. Literature and Science. In: THE LITERARYchronicle for the year of 1825. London: Davidson, 1825, p. 46.

THIERRY, Augustin. Lettres sur l'bistoire de France: pour servir d'introduction à l'étude de cette histoire. Paris: Sautelet/Ponthieu, 1827.

VICTOR, Jayme. Ferdinand Denis. O Ocidente, ano 13, v. 13, n. 420, p. 187-90, ago. 1890.

\section{REFERÊNCIAS GERAIS}

BAREL, Ana Beatriz Demarchi. Um romantismo a oeste: modelo francês, identidade nacional. São Paulo: Annablume, 2002.

BLIX, Göran. From Paris to Pampeii: French Romanticism and Cultural Politics of Archaeology. Philadelphia: University of Pennsylvania Press, 2009.

CANDIDO, Antonio. Literatura e Sociedade. Rio de Janeiro: Ouro sobre azul, 2008.

CEZAR, Temístocles. Entre antigos e modernos: a escrita da história em Chateaubriand. Ensaio sobre historiografia e relatos de viagem. Almanack Braziliense, v. 11, p. 26-33, maio 2010.

CEZAR, Temístocles. Narrativa, cor local e ciência: notas para um debate sobre o conhecimento histórico do século XIX. História UNISINOS, v. 8, n. 10, p. 11-34, 2004.

COSTA LIMA, Luiz. À maneira de prefácio. In: ROUANET, Maria Helena. Eternamente em berço esplêndido: a fundação de uma literatura nacional. São Paulo: Siciliano, 1991, p. 11-3.

DAHEUR, Jawad; HAMM, Elisabeth. La nature mise en scène / Naturinszenierungen: introduction. Trajectoires, v. 12, 2019. Disponível em: https://journals.openedition.org/ trajectoires/3395. Acesso em: 20 fev. 2020.

DETIENNE, Marcel. A invenção da mitologia. Rio de Janeiro: José Olympio, 1992.

FERREIRA, Marieta de Moraes. História do tempo presente: desafios. Cultura Vozes, v. 94, n. 3, p. 111-24, maio/jun. 2000.

FINAZZI-AGRÒ, Ettore. Tropos e trópicos: Ferdinand Denis e o imaginário brasileiro. Revista Brasileira, fase 8, ano 1, n. 71, p. 211-22, 2012.

FONSECA, Carlos Alberto. As rubricas no teatro sânscrito. ITINERÁRIOS, v. 5, p. 61-85, 1993.

FOUCAULT, Michel. A escrita de si. In: . Ditos e Escritos. Rio de Janeiro: Forense Universitária, 2004, p. 144-62.

GAUCHET, Marcel. Les lettres sur l'histoire de France d'Augustin Thierry. In: NORA, Pierre (dir.). Les lieux de mémoire. Paris: Gallimard, 1986. t. 2, v. 1, p. 247-316.

GAUCHET, Marcel. Philosophie des sciences historiques: le moment romantique. Paris: Seuil, 2002. 
GOSSMAN, Lionel. Augustin Thierry and Liberal Historiography. With introductory comments by Hayden White. Middletown: Wesleyan University Press, 1976.

GUMBRECHT, Hans Ulrich. Modernização dos Sentidos. São Paulo: Ed. 34, 1998.

HARTOG, François. Regimes de historicidade: presentismo e experiências do tempo. Belo Horizonte: Autêntica, 2014.

KOSELLECK, Reinhart. Futuro passado: Contribuição à semântica dos tempos históricos. Tradução de Wilma Patrícia Maas, Carlos Almeida Pereira e revisão de César Benjamin. Rio de Janeiro: Contraponto; PUC-Rio, 2006.

KURY, Lorelai. No calor da Pátria. Revista USP, n. 72, p. 80-9, dez./fev. 2006-7.

LABORIE, Jean Claude. Estudo de mediações: o caso de Ferdinand Denis. Ponto-e-vírgula, v. 13, p. 66-77, 2013.

LUKÁCS, Georg. La novela Histórica. Altos: Era, 1966.

MEDEIROS, Bruno Franco. Plagiário, à maneira de todos os historiadores. Jundiaí: Paco, 2012.

MELLON, Stanley. The political uses of history: a study of historians in the French restoration. Stanford: Stanford University, 1958.

MOMIGLIANO, A. As raízes clássicas da historiografia moderna. Bauru: Edusc, 2004.

MONOD, Gabriel. Introduction: du progrès des études historiques en France depuis le XVIe Siécle. Revue Historique, n. 1, p. 5-38, 1876.

MOREAU, Pierre. Introduction. In: DENIS, Ferdinand. Journal (1829-1848). Fribourg: Université de Fribourg, 1932. (Collectanea Friburgensia, 30).

NOIRIEL, Gérard. Naissance du métier d'historien. Genèses, v. 1, p. 58-85, 1990.

NORA, Pierre. Les lieux de mémoire. Paris: Gallimard, 1986. t. 2.

OLIVEIRA, Maria Edith Maroca de Avelar Rivelli de. Letras de memória: o indígena como cronótopo da narrativa do passado no período imperial, dos estudos históricos ao romance indianista de José de Alencar (1820-1870). Dissertação (Mestrado em História) - Programa de Pós-Graduação em História, Universidade Federal de Ouro Preto, Mariana, 2011.

PERTUÉ, Michel. Royer-collard et la charte de 1814. Historia Constitucional, n. 15, p. 23-69, enero-dic. 2014. Disponível em: https:/ / www.redalyc.org/articulo.oa?id=259031826003. Acesso em: 22 dez. 2016.

RANGEL, Marcelo de Mello. Poesia, história e economia politica nos Suspiros Poéticos e Saudades e na Revista Niterói: os primeiros Românticos e a civilização do Império do Brasil. Tese (Doutorado em História) - Programa de Pós-graduação em História Social da Cultura, PUC-Rio, Rio de Janeiro, 2011. 
RAZZINI, Márcia. Um compadre do Brasil - Ferdinand Denis. Letras de hoje, v. 30, n. 3, p. 125-7, set. 1995.

REIZOV, Boris G. L'Historiographie Romantique Française (1815-1830). Moscou: Éditions en langues étrangères, 1962.

ROUANET, Maria Helena. Eternamente em berço esplêndido: a fundação de uma literatura nacional. São Paulo: Siciliano, 1991.

TRIPOLI, Mailde J. O caminho das pedras: passos iniciais de uma pesquisa historiográfica. Letras de hoje, v. 30, n. 3, p. 117-23, set. 1995.

TURIN, Rodrigo. Os antigos e a nação: algumas reflexões sobre os usos da antiguidade clássica no IHGB (1840-1860). L'Atelier du Centre de recherches historiques, v. 7, 2011. Disponível em: https://journals.openedition.org/acrh/3748. Acesso em: 24 fev. 2020. DOI: https://doi. org/10.4000/acrh.3748

VERMEULEN, Han F. The German invention of Völkerkunde: Ethnological discourse in Europe and Asia, 1740-1798. In: EIGEN, Sara; LARRIMORE, Mark (ed.). The German invention of race. Albany: State University of New York Press, 2006. p. 123-245.

ZILBERMAN, Regina. "Cor local" e história da literatura. Légua \& meia: Revista de literatura e diversidade cultural, ano 13, n. 6, p. 9-21, 2014.

ZILBERMAN, Regina. Ferdinand Denis e o Resumo de História Literária. In: DENIS, Ferdinand. Resumo da história literária de Portugal seguido do resumo da história literária do Brasil. Tradução, apresentação e notas de Regina Zilberman. Rio de Janeiro: Makunaíma, 2018, p. 3152. Disponível em: http://edicoesmakunaima.com.br/catalogo/4-historia-da-literatura/32resumo-da-historia-literaria-de-portugal-seguido-do-resumo-da-historia-literaria-do-brasil. Acesso em: 12 fev. 2019.

ZILBERMAN, Regina. Ferdinand Denis e o século XVI - o Moderno em disputa. Todas as letras X, v. 16, n. 2, p. 14-26, nov. 2014.

ZILBERMAN, Regina. Ferdinand Denis e os paradigmas da história da literatura. Revista do Programa de Pós-Graduação em Letras da Universidade de Passo Fundo, v. 2, n. 1, p. 137-47, jan./ jun. 2006.

ZILBERMAN, Regina. O Resumo de História Literária, de Ferdinand Denis: história da literatura enquanto campo de investigação. Veredas, v. 19, p. 121-44, 2013. 